continuation of a long-term warming. However, the warming appears to have been accelerated towards the present day.

Integration of the complementary information greatly improves the comparability of the reconstructed temperatures and the Crowley (2000) radiative forcing history (Fig. 2). Analysis of the reconstructed temperature and radiative forcing series offers an independent estimate of the transient climate-forcing response rate of $0.4-0.7 \mathrm{~K}$ per $\mathrm{Wm}^{-2}$ and predicts a temperature increase of $1.0-1.7 \mathrm{~K}$ in 50 years (Huang, 2004).

\section{Discussion}

It is worth pointing out that the integrated reconstruction is not a simple superposition of the high frequencies of the multi-proxy reconstruction on the lower frequencies of the borehole reconstruction. The integrated reconstruction consolidates information given in the subsurface temperature data and in the a priori model. For the 20th century, where the a priori multi-proxy model is well trained by the meteorological record, little alternation is made through the inversion. At very long periods, the subsurface temperature data provide information that is weak or absent in the multi-proxy reconstruction. At intermediate periods both the a priori model and subsurface data provide important constraints.

The improvement in the comparability between climate reconstruction and the radiative forcing series is a validation of the climate information integration strategy. The good agreement between the integrated reconstruction and the forcing model confirms that there are both natural and anthropogenic factors influencing the recent warming.

\section{ACKNOWLEDGEMENTS \\ Support for this study comes from NSF Grant ATM-0317572. The author thanks Henry Pollack and Po-Yu Shen for stimulat- ing discussions. The global database of}

borehole temperatures is hosted by the University of Michigan (www.geo.Isa. umich.edu/climate) and accessible at World Data Center-A for Paleoclimatology Data (www.ncdc.noaa.gov/paleo/borehole).

Note

The time series of this integrated reconstruction can be downloaded from www. ncdc.noaa.gov/paleo/pubs/huang2004.

\section{REFERENCES}

Crowley T.J., 2000: Causes of climate change over the past 1000 years. Science, 289: 270-277.

Huang, S., Pollack, H. N., and Shen, P.Y., 2000: Temperature trends over the past five centuries reconstructed from borehole temperatures. Nature, 403: 756-758.

Huang, S., 2004: Merging Information from Different Resources for New Insights into Climate Change in the Past and Future. Geophys. Res, Lett., 31: L13205, doi:10.1029/2004GL019781.

Jones, P.D., New, M., Parker, D.E., Martin, S., Rigor, I.G., 1999: Surface air temperature and its changes over the past 150 years. Rev. Geophys., 37:173199.

Mann, M.E., Bradley, R.S., Hughes, M.K., 1999: Northern hemisphere temperatures during the past millennium: inferences, uncertainties, and limitations. Geophys. Res. Lett., 26:759-762.

\title{
Can models of abrupt climate change be tested from sea level reconstructions?
}

\author{
Charles Jackson ${ }^{1}$, Yurun LiU ${ }^{2}$ and Olivier Marchal ${ }^{3}$ \\ ${ }^{1}$ Institute for Geophysics, University of Texas at Austin, USA; charles@ig.utexas.edu \\ ${ }^{2}$ Department of Physics, University of Texas at Austin, USA \\ ${ }^{3}$ Woods Hole Oceanographic Institution, USA
}

\section{Introduction}

As hypotheses concerning the origin of abrupt climate change accumulate, there is an increasing need to synthesize data and to develop methods that may help assess their strengths and inconsistencies. Understanding the mechanisms of abrupt climate change is particularly challenging because of the uncertainties in paleoclimate observations and in our knowledge of the physics of the climate system. Among the techniques that can be used to piece together the common elements of noisy observations given knowledge of a system's physics are so-called "inverse methods". In particular, stochastic inverse modeling provides a way to navigate the uncertainties in data and models, and deal with the possibility of multiple solutions (inferences). Most notably, it can re-express the problem of abrupt climate change in terms of its implications for what we should see in observations if models provide adequate representation of the processes that exist in nature. Here, we demonstrate the potential of this approach (i) by estimating the changes in global sea level implied by the combination of a Greenland ice core paleotemperature record during the last glacial period, with a highly simplified model of the buoyancy-driven ocean circulation, and (ii) by comparing these changes to reconstructions of global sea level during this period. The comparison provides a test of the consistency between the various datasets and a test of the hypothesis of a freshwater forcing of abrupt climate change.

\section{Freshwater forcing hypothesis}

The freshwater forcing hypothesis to explain abrupt climate change involves changes in the freshwater supply to the North Atlantic Ocean through instabilities of the large continental ice sheets that covered the high northern latitudes during the last glacial period. A key part of this hypothesis is the capability of the ocean meridional circulation and of the attendant poleward heat flux to suddenly switch state and hold the climate system in a new state for hundreds to thousands of years. This possibility is suggested by a hierarchy of ocean models that exhibit multiple equilibria of the meridional circulation and that demonstrate the potential of surface freshwater forcing to initiate transitions between the equilibria. Thus, a hysteresis exists within 


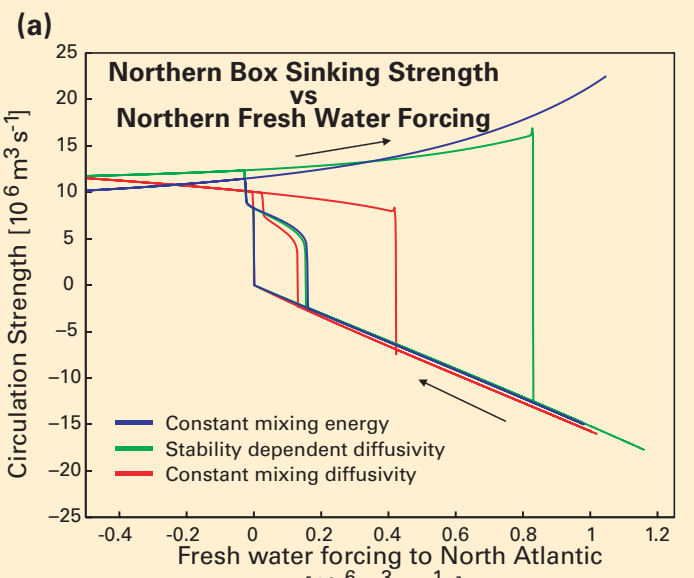

$\left[10^{6} \mathrm{~m}^{3} \mathrm{sec}^{-1}\right]$

(c)

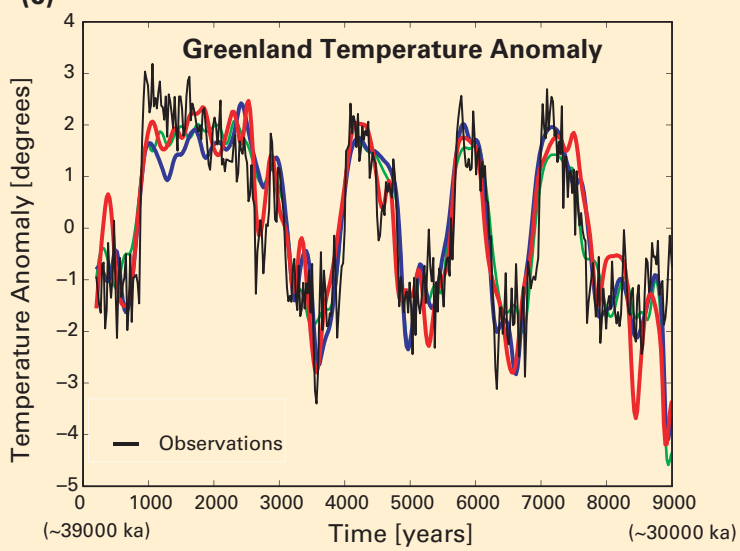

(b)

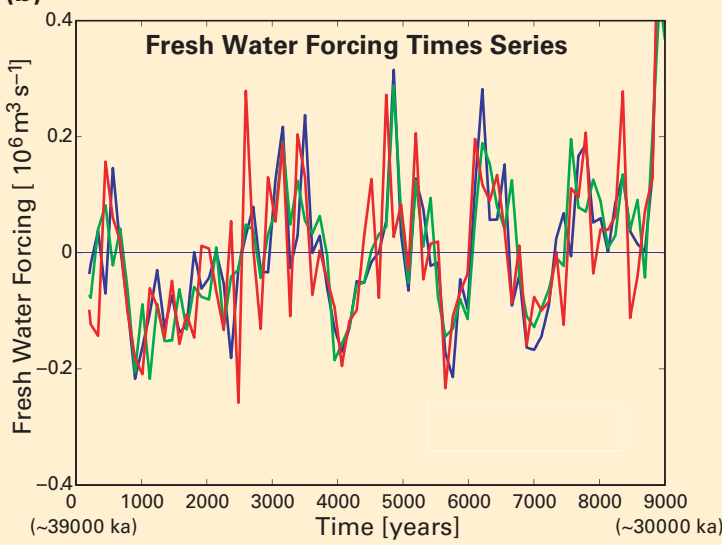

(d)

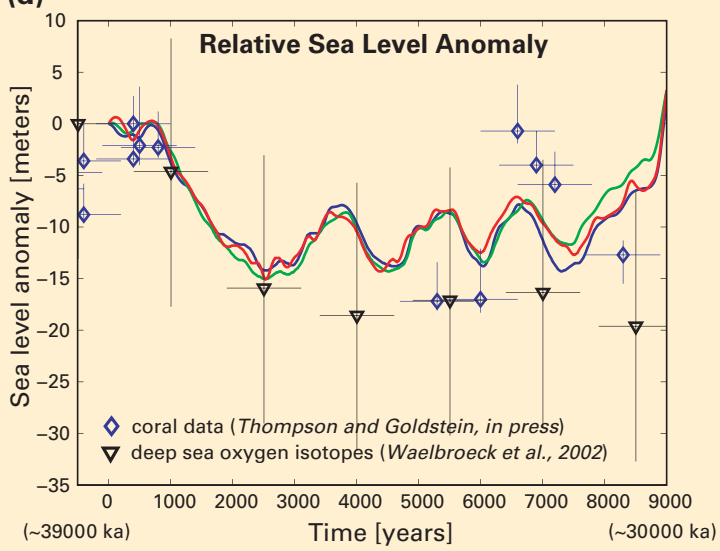

Figure 1: Inverse modeling of abrupt climate change: $\boldsymbol{A}$ ) equilibrium sensitivity of three models to freshwater forcing of the North Atlantic, B) freshwater forcing history required to match Greenland data, C) model reconstructions of Greenland data, and $\mathbf{D}$ ) effect of freshwater forcing on sea level as compared to observations with estimates of uncertainty.

these models, such that multiple circulation strengths occur for the same rate of freshwater supply to the high latitudes. The freshwater hypothesis is apparently supported by the observation of ice rafted debris in North Atlantic sediments during the cold phases of abrupt climate change. Records of global sea level, which provide an integrated measure of the freshwater forcing history, would provide another test for this hypothesis.

\section{Uncertain physics}

Among the major uncertainties in numerical models of the ocean circulation is the representation of sub-grid scale phenomena. The most common assumption is that the transport of properties such as momentum, heat, and salt at small scales acts as a diffusion of these variables at large scales that is effectively resolved by the models. Most notably, the issue of the representation of small-scale vertical mixing is gaining a lot of attention, following a claim that this mixing may actually force the meridional circulation and its attendant heat flux (Munk and Wunsch, 1998). According to a scaling theory of the oceanic thermocline based on various approximations in the equations of motion, different assumptions about vertical mixing leads to a qualitatively different response of the meridional circulation to the surface freshwater forcing (Fig. 1a). The assumptions considered are representative of the range of what is physically justifiable, including mixing represented with constant vertical diffusivity, stability-dependent diffusivity, and fixed mixing energy. The solutions are generated from a 4-box model of the global meridional circulation, thereby extending the single-hemisphere model study of Nilsson and Walin (2001).

\section{Bayesian stochastic inversion}

For each of the three mixing representations, we use a method of
"Bayesian Stochastic Inversion" (Jackson et al., 2004) to estimate the time evolution of freshwater forcing (Fig. 1b) that permits each model to reproduce the Greenland ice core record between 39-30 ka BP (Fig. 1c). The method works by randomly guessing the freshwater forcing for 81 evenly spaced points along the 9 kyr interval and using information about the effects of this guess on model-data mismatch to guide subsequent forcing histories. This process is repeated multiple times and the statistics of the results are collected. Thus, solutions may be represented by a multi-dimensional probability distribution indicating the relative likelihood, the uncertainties, and the dependencies of the different quantities that are inferred from the original data. Illustrated in Figure $1 \mathrm{~b}-\mathrm{c}$ are the optimal (most likely) solutions that provide the minimum mismatch between the data and the model. 


\section{Inversion results and implications}

The global sea level variations implied by the freshwater forcing histories for the three different mixing formulations are nearly identical; each showing a drop of $\sim 15 \mathrm{~m}$ during the prolonged $\sim 3 \mathrm{kyr}$ warm phase starting around $38 \mathrm{ka}$ BP or model year 1000 . The subsequent sequence of warm-cold phases (between 35-30 ka BP) is associated with $\sim 5 \mathrm{~m}$ variations in sea level. The timing and amplitude of these sea level variations are not inconsistent with two independent reconstructions, given their uncertainties (Thompson and Goldstein, in press; Waelbroeck et al., 2002). Although the relatively large uncertainties preclude a solid conclusion, the comparison illustrates the level of accuracy that is necessary for a more stringent test of the freshwater hypothesis from the sea level record. Furthermore, these results highlight the potential importance of ice sheet growth in maintaining a negative high latitude freshwater balance for the phases of sustained warmth, with the length of the warm phases being directly related to the amplitude of the sea level fall.

The striking similarities among the three mixing formulations may be surprising considering the very different steady state response of each model to freshwater forcing (Fig. 1a). We find that the processes governing the model's transient response to freshwater forcing to be initially very similar and only begin to diverge after a few hundred years. In all cases, the imposition of a high latitude freshening reduces meridional density gradients and, hence, the strength of the meridional circulation with changes in vertical mixing lagging. A more thorough examination of the causes of this similarity is being investigated.

\section{Conclusion}

This stochastic inverse model exercise suggests that the freshwater forcing hypothesis of abrupt climate change is consistent with the most direct estimates of past sea level, assuming that (i) our interpretation of the Greenland record in terms of temperature changes in the high northern latitudes is correct, and (ii) the highly simplified model we have used captures the relevant physics. This consistency does not depend on the formulation of vertical mixing in the model. Whether more complete models are sensitive to the formulation of vertical mixing in their transient response to high latitude freshening warrants further investigation.

\section{REFERENCES}

Jackson, C. M. Sen, and Stoffa, P. 2004: An Efficient Stochastic Bayesian Approach to Optimal Parameter and Uncertainty Estimation for Climate Model Predictions, Journal of Climate, 17(14), 2828-2841.

Munk, W., and Wunsch, C., 1998: Abyssal recipes

II: Energetics of tidal and wind mixing, Deep Sea Research Part I: Oceanographic Research Papers, 45(12), 1977-2010.

Nilsson, J., and Walin, G., 2001: Freshwater forcing as a booster of thermohaline circulation. Tellus, 53A, 629-641.

Thompson, W. G. and Goldstein, S.L., in press: A radiometric calibration of the SPECMAP timescale, Quaternary Science Reviews.

Waelbroeck, C., Labeyrie, L., Michel, E., Duplessy, J.C., McManus, J.F., Lambeck, K., Balbon, E., and Labracherie M., 2002: Sea-level and deep water temperature changes derived from benthic foraminifera isotopic records, Quaternary Science Reviews, 21(1-3), 295-305.

\title{
Late Holocene hydrological variability in ombrotrophic peatlands of eastern North America
}

\author{
Stephen T. Jackson ${ }^{1}$, Robert K. Booth ${ }^{2}$, Yongsong Huang ${ }^{3}$, Elise G. Pendall ${ }^{1}$, Jonathan E. Nichols ${ }^{3}$, Thomas A. Minckley ${ }^{1}$ and \\ Meghan TayloR ${ }^{1}$ \\ 'Department of Botany, University of Wyoming, Laramie, USA; jackson@uwyo.edu \\ 2Department of Earth and Environmental Sciences, Lehigh University, Bethlehem, USA \\ ${ }^{3}$ Department of Geological Sciences, Brown University, Providence, USA
}

\section{Introduction}

Ombrotrophic peatlands, particularly "raised bogs", comprise a rich but underutilized source of Holocene paleoenvironmental records for North America. These peatlands, which are scattered from the Atlantic to the Pacific coasts at latitudes between $42^{\circ}$ and $65^{\circ} \mathrm{N}$, are dominated by Sphagnum moss and a few vascular plants, have elevated surfaces, and receive all surface moisture directly from the atmosphere. Water tables of these bogs are perched above the groundwater table, and most water loss is through evapotranspiration. Accordingly, ombrotrophic bogs are hydrologically sensitive to precipi- tation and temperature variations across a range of temporal scales, from seasonal to millennial.

Sedimentary records from ombrotrophic peats can span 1000-10,000 years, with temporal resolution ranging from sub-centennial to sub-decadal depending on accumulation rates. A variety of paleoenvironmental proxies, including testate-amoebae, peat humification, pollen, plant macrofossils, charcoal, stable isotopes $(\mathrm{H}, \mathrm{C}, \mathrm{O})$, and biomolecular markers, are preserved in these peats. We are conducting a study of all of these proxies in late Holocene peats from raised bogs along a transect spanning the Great Lakes/
St. Lawrence corridor, from Minnesota to Maine. We are coupling these paleoclimate reconstructions with extensive modern calibration studies and investigations of historical climate variability. These studies are leading to detailed multivariate climatic reconstructions and development and testing of hypotheses regarding the underlying climate dynamics.

\section{Peatland records of drought synchrony in the Central United States}

Peat records from sites $1000 \mathrm{~km}$ apart in north-central Minnesota (Hole Bog) and southeastern Michigan (Minden Bog) span the past 